\title{
PP21
}

\section{LIGHTING REQUIREMENTS FOR ADAPTIVE DRIVING BEAM (ADB) TO IMPROVE TARGET VISIBILITY WHEN ONCOMING HEADLIGHT GLARE EXISTS}

Yukio Akashi et al.

DOI 10.25039/x46.2019.PP21

from

CIE x046:2019

Proceedings

of the

29th CIE SESSION

Washington D.C., USA, June 14 - 22, 2019

(DOI 10.25039/x46.2019)

The paper has been presented at the 29th CIE Session, Washington D.C., USA, June 14-22, 2019. It has not been peer-reviewed by CIE.

(C) CIE 2019

All rights reserved. Unless otherwise specified, no part of this publication may be reproduced or utilized in any form or by any means, electronic or mechanical, including photocopying and microfilm, without permission in writing from CIE Central Bureau at the address below. Any mention of organizations or products does not imply endorsement by the CIE.

This paper is made available open access for individual use. However, in all other cases all rights are reserved unless explicit permission is sought from and given by the CIE.

CIE Central Bureau

Babenbergerstrasse 9

A-1010 Vienna

Austria

Tel.: +43 17143187

e-mail: ciecb@cie.co.at

www.cie.co.at 


\title{
LIGHTING REQUIREMENTS FOR ADAPTIVE DRIVING BEAM (ADB) TO IMPROVE TARGET VISIBILITY WHEN ONCOMING HEADLIGHT GLARE EXISTS
}

\author{
Akashi, Y. ${ }^{1}$, Miyazaki, T. ${ }^{1}$, Maeda, H. ${ }^{1}$, Shibata, Y. ${ }^{2}$, Ishida H. ${ }^{2}$ \\ ${ }^{1}$ University of Fukui, Fukui, JAPAN, ${ }^{2}$ Koito Manufacturing Co., LTD., Shizuoka, JAPAN \\ akashi@u-kukui.ac.jp
}

DOI 10.25039/x46.2019.PP21

\begin{abstract}
To identify lighting requirements for ADB systems to help drivers detect off-axis potential hazards when oncoming headlight glare exists in a night-time roadway, we conducted target detection tests under various experimental conditions in a laboratory. In the experiment, we used a simulated ADB system which can illuminate only targets locally and therefore increase the luminance contrasts of the targets. The experimental results suggest that the ADB system is more efficient lighting methods than conventional forward lighting systems which illuminate the entire visual field to increase drivers' adaptation luminance levels. Based on the detection rates, we also determined requirements for threshold luminance contrast for targets with oncoming headlight glare.
\end{abstract}

Keywords: Automotive lighting, Adaptive driving beam, Target visibility

\section{Introduction}

Driving is a demanding multitasking activity. A driver must maintain a vehicle within a traffic lane while keeping its speed below the regulation speed and following other vehicles. Additionally, the driver must quickly detect oncoming traffic and obstacles on the roadways to avoid collisions with potential hazards. So, the driver must conduct on-axis tracking tasks and off-axis detection tasks simultaneously. Oncoming vehicles' headlamps often cause disability glare in night-time drives. Such disability glare reduces luminance contrasts of targets against the background, resulting in reduced target visibility (Adrian, 1969; CIE, 1981; Terai et al., 2017). Unfortunately, many traffic accidents under such conditions have occurred in the world.

Adaptive driving beam (ADB) systems have recently been developed to prevent drivers from meeting with the above-described traffic accidents. An ADB system consists of an array of LEDs to change its luminous intensity distribution by turning on/off and dimming each of the arrayed LEDs. When a car-mounted infra-red camera detects a potential hazard on a roadway, a few of the arrayed LEDs, assigned to aim at a local area where the potential hazard is located, are turned on and aim at the target locally while minimizing glare to preceding and oncoming traffic. By illuminating the local area with the ADB system it is possible not only to increase illuminance on the target but also to increase the luminance contrast of the target against the background. Although recent studies proved that ADBs improved drivers' visual performance (Bodrogi et al., 2015; Bullough et al., 2016), it is still unclear how much light is needed for drivers to detect the target with the aid of ADBs.

To identify lighting requirements for $A D B$ systems to help drivers detect off-axis potential hazards when oncoming headlight glare exists in night-time roadways this study conducted target detection tests under various experimental conditions in a laboratory. Based on the detection rates, threshold luminance contrast requirements for targets were determined under each of the experimental conditions.

\section{Methods}

This study conducted two experiments. Both the experiments measured subjects' detection rates for targets peripherally presented when glare sources exist in the subjects' visual fields. To develop an experimental setup, we considered the following experimental scenario. 


\subsection{Experimental scenario}

To determine the experimental scenario, we referred to a study (Aoki et al., 2011) which observed pedestrians' behaviours to understand how they make recognition-based decisions to avoid hazards. The Aoki et al.'s study found that the following traffic condition is very likely to induce traffic accidents. Figure 1 also depicts an example for the traffic condition.

(1) A driver manipulates a car at $50 \mathrm{~km} / \mathrm{h}$ on a nighttime local two-lane roadway around which there are few street luminaries.

(2) An oncoming car with low beam headlamps in the opponent lane approaches to the driver's car and causes disability glare to the driver.

(3) A pedestrian stands at $70 \mathrm{~m}$ away from the driver's car on the shoulder of the roadway. The pedestrian intends to come across the roadway from the right to the left after the oncoming car passes the pedestrian.

The distance of $70 \mathrm{~m}$ was selected based on Aoki et al.'s study. They found the distance of 70 $\mathrm{m}$ was the one at which a normal pedestrian thinks that he or she can come across the roadway before the oncoming car at $50 \mathrm{~km} / \mathrm{h}$ passes by him or her. However, if the pedestrian actually comes across the roadway, the oncoming car often collide with the pedestrian. This presenting study attempted to simulate such a hazardous traffic condition in a laboratory.

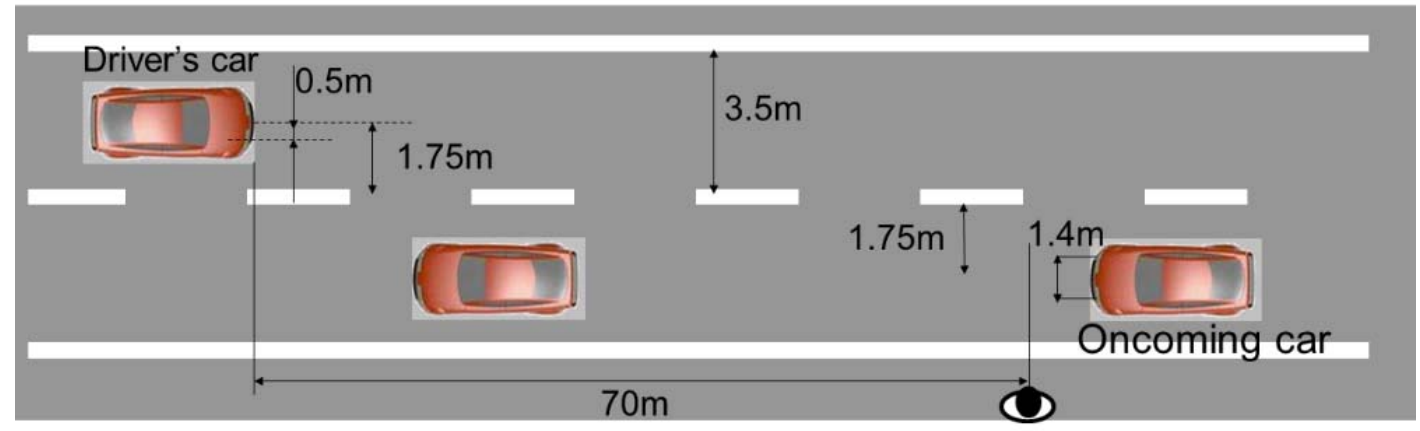

Pedestrian

Figure 1 - Traffic condition, likely to cause a traffic accident.

The above-described traffic condition is viewed by the driver as depicted in Figure 2. The left headlamp is located at an eccentricity angle of 1.9 degrees while the right headlamp at 3.0 degrees. The pedestrian stands on the road shoulder at an eccentricity angle of 4.7 degrees. To simulate such a scene under the hazardous traffic condition the following experimental setup was developed.

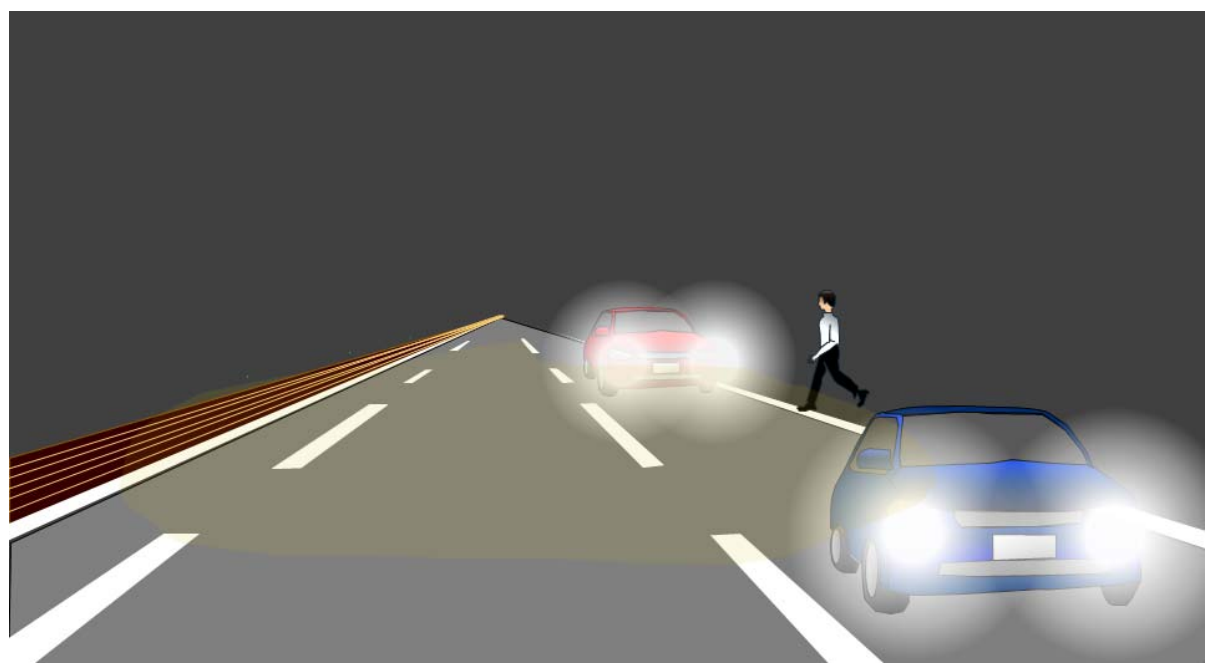

Figure 2 - A driver's view of the above-described hazardous traffic condition 


\subsection{Experimental setup}

The experimental setup simulated a night-time driving context in which a driver conducted a tracking task in the foveal vision and a target detection task in the peripheral vision simultaneously while oncoming headlamps provide disability glare. Figure 3 shows the experimental setup which consisted of a target presentation apparatus, a chinrest, a manual switch, a personal computer and a lighting fixture. The target presentation apparatus will be described later in this subclause. The chinrest was for a subject to maintain his/her eye positions as constant as possible. The manual switch was for the subject to signal his/her peripheral target detections. Then, the manual switch sent the signal to the personal computer. The personal computer was to present peripheral targets and receive the subject's responses. The personal computer measured a response time as a duration of time between when a target was presented and when the subject pressed the manual switch. The lighting fixture was used to illuminate the target presentation apparatus uniformly so that the background luminance was maintained at $0.2 \mathrm{~cd} / \mathrm{m}^{2}$ under all experimental conditions.

The target presentation apparatus was composed of a grey partition, a tracking task apparatus, peripheral targets, a spot beam box and a pair of oncoming headlamps. The grey partition was a $900 \mathrm{~mm}$ high, $1500 \mathrm{~mm}$ wide and $5 \mathrm{~mm}$ thin styrene foam board pasted with a black cardboard with a reflectance of $5 \%$ on its both surfaces. In the grey partition embedded were the tracking task apparatus, peripheral targets and two sets of oncoming headlamps. Figure 4 shows the layout of the target presentation apparatus which simulated the hazardous traffic condition shown in Figure 3. The tracking task apparatus was a $10 \mathrm{~mm}$ wide, $20 \mathrm{~mm}$ high and $8 \mathrm{~mm}$ thick LED numerical signboard, consisting of seven LED segments, which presented one of one-digit numbers from zero to nine and changed the number every two-to-five seconds in random order. The foveal tracking task was for a subject to read aloud the number as soon as the subject notice the number changed so the subject could keep fixating on the centre of the visual field. The peripheral targets were circular light spots that were projected by the spot beam box, and were located at 3.9 and 5.0 degrees to the right from the centre of the tracking task apparatus. Each of the three targets had a diameter of 0.37 degrees that simulated a body of a pedestrian who stood $70 \mathrm{~m}$ away from the driver. The spot beam box was a $100 \mathrm{~mm}$ high, $80 \mathrm{~mm}$ wide and $90 \mathrm{~mm}$ deep black aluminium box in which a lens, an LED chip and an electronic circuit were installed. The first set of headlights were located at 9.1 degrees and 14.4 degrees while the second set of headlights were located at 1.2 degrees and 1.9 degrees.

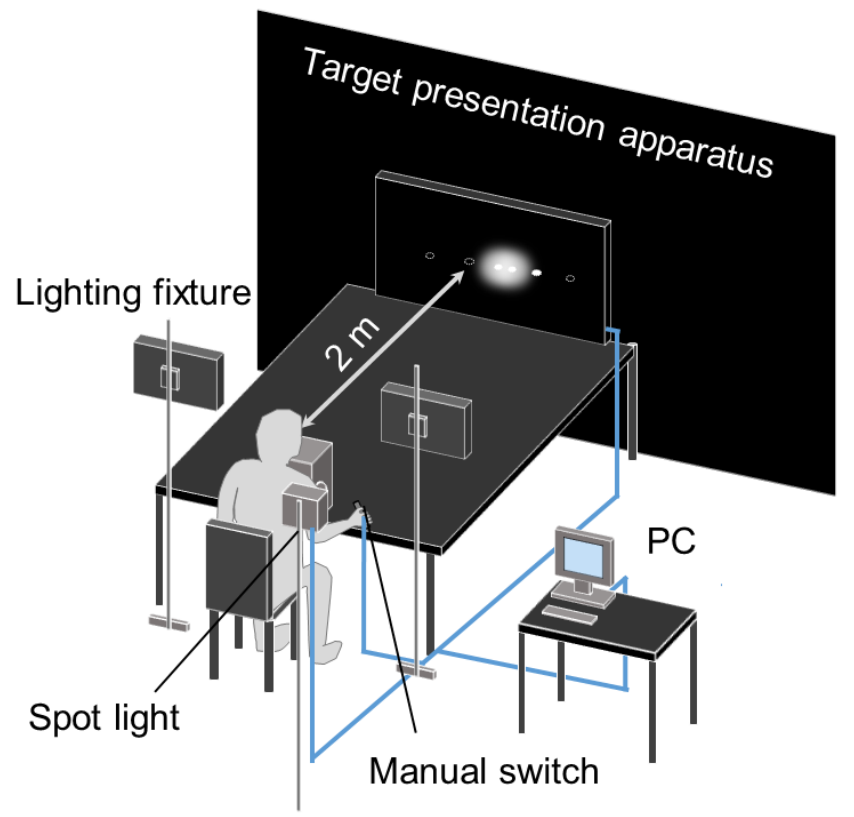

Figure 3 - Experimental setup 


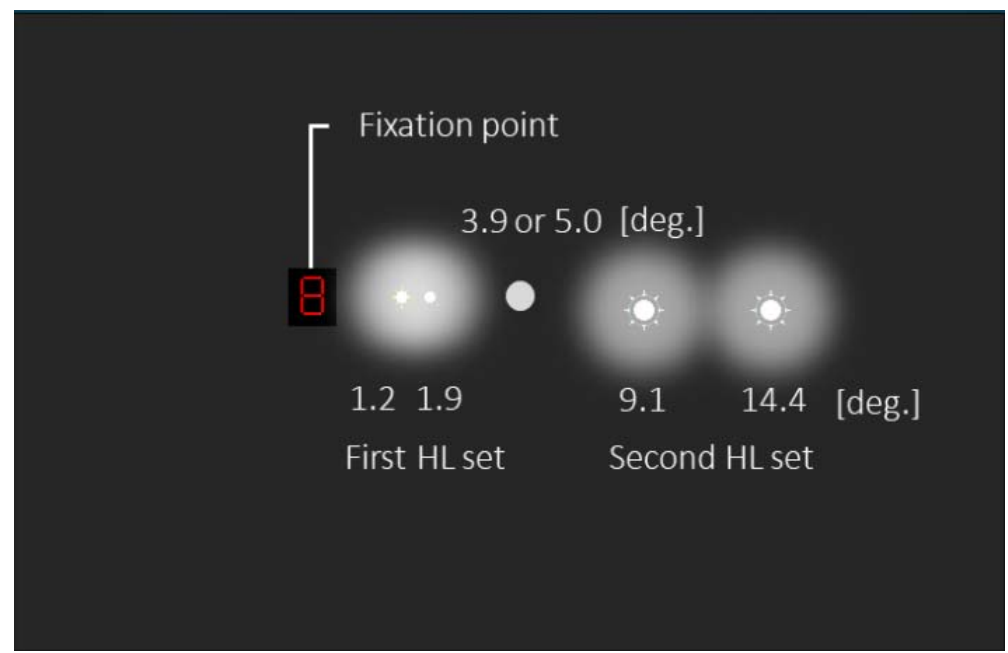

Figure 4 - Target presentation apparatus viewed by a subject

\subsection{Experimental conditions}

Table 1 shows experimental conditions. In the experiment, a target was presented on the background with a uniform luminance of $0.2 \mathrm{~cd} / \mathrm{m}^{2}$ at an eccentricity angle of either 3.9 or 5.0degrees. The background luminance of $0.2 \mathrm{~cd} / \mathrm{m}^{2}$ was determined based on a luminance measurement of a roadway surface at $70 \mathrm{~m}$ illuminated by a pair of low-beam headlamps. The conditions of the two sets of oncoming headlights were (1) both sets are off (both-off), (2) the first set was on (1 $1^{\text {st }}-$ on), ( 3 ) the second set was on $\left(2^{\text {nd }}-\right.$ on), and (4) both sets were on (bothon). Illuminance levels on the subject's eyes were $0 \mathrm{Ix}, 1.04 \mathrm{Ix}, 0.66 \mathrm{Ix}$ and $1.70 \mathrm{Ix}$, respectively. These illuminance levels were determined based on illuminance measurements at the driver's eyes when a pair of oncoming low-beam headlamps were turned on at $90 \mathrm{~m}$ and $30 \mathrm{~m}$ in the opponent lane for the first set of headlamps and the second set of headlamps respectively in a real field. Five levels of luminance contrast were selected so that the threshold (50-percentile) luminance contrast can be identified. A dependent variable was a target detection rate. Because a subject viewed the targets by binocular vision, there was no effect of blind spot on target detection.

If a subject does not press the switch for $3000 \mathrm{~ms}$ after a target was presented, we regarded the situation as the subject could not detect the target. Then, the target presentation was discontinued, and the next target was presented at an interval randomized between $1000 \mathrm{~ms}$ and $3000 \mathrm{~ms}$. Each target was presented 36 times. At the condition with an illuminance at eyes of $0 \mathrm{Ix}$, the glare light source was turned off. Then, the subject detected a target after adapting the uniform-luminance background. The subject was instructed to press the switch as soon as detecting the target.

Table 1 - Experimental conditions

\begin{tabular}{|c|c|}
\hline Individual variables & Levels \\
\hline Target position [degrees] & $3.9,5.0$ \\
\hline $\begin{array}{l}\text { Oncoming headlight glare (Two sets of headlights) } \\
\text { (IIluminance at eyes by oncoming headlamps [Ix]) }\end{array}$ & $\begin{array}{l}\text { both-off, } 1^{\text {st }} \text {-on, } 2^{\text {nd }} \text {-on, both-on } \\
(0,1.04,0.66,1.70)\end{array}$ \\
\hline Luminance contrast of target against background & $0.05,0.1,0.2,0.3,0.4$ \\
\hline
\end{tabular}

\subsection{Light sources and subjects}

A 5000K LED illuminated the background uniformly. A 5220K LED illuminated the target regionally. A 5520K LED illuminated the subject's eyes as a glare source. These LEDs are normally used for low-beam forward lighting. The S/P ratios of the three LEDs were 1.47, 1.40, and 1.81 respectively. Figure 5 shows their spectral power distributions. 
In the experiment, 16 subjects (male: 10, female: 6) with ages between 21 and 25 years old participated. All the subjects except three had driver licenses, and they practiced the whole procedure before the experiment. An experimenter instructed the procedure of the experiment to the subjects. Each subject started the experiment after signing an informed consent form. The experimenter emphasized that the subjects had to fixate on the tracking task apparatus in the centre of the visual field, and detect a peripheral target at the same time.

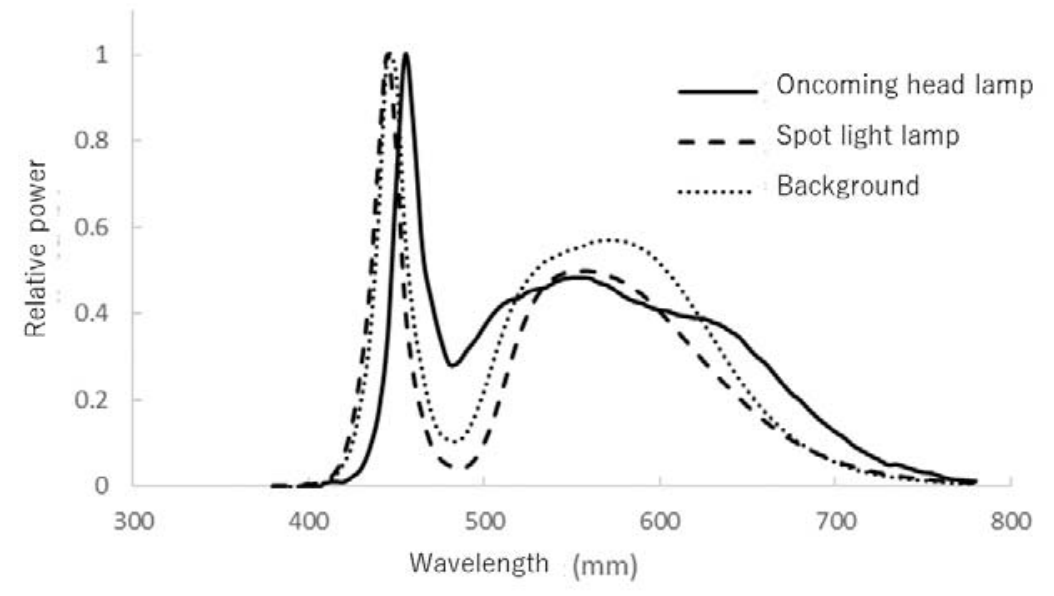

Figure 5 - Spectral power distributions

\subsection{Experimental procedure}

The experiment was conducted by following the procedure listed below.

(1) An experimenter escorted a subject to the chair in front of the target presentation apparatus. Then, the subject adapted to the brightness $\left(0.2 \mathrm{~cd} / \mathrm{m}^{2}\right)$ of the background of the apparatus for more than 10 minutes. During the adaptation period, the experimenter gave an instruction to the subject.

After the instruction, the subject wore a pair of earplugs so that the subject could not hear of target-flip sounds.

(2) The subject practiced detecting targets ten times so thirty times in total. After the subject's practice, the experimenter turned on the glare source when the glare source is needed to be presented.

(3) The subject adapted to the brightness of the scene for one minute. Then, the experimenter started the target presentation program. All targets including dummy targets were presented at a random order. The computer recorded the subject's reaction times.

(4) The experimenter repeated the procedure (3) for the other experimental conditions. It took each subject about an hour to complete the experiment. Each of ten target presentations was repeated 36 times (360 presentations in total).

\section{Experimental results and discussion}

Figures 6 and 7 show target detection rates for the 3.9-deg. and 5.0-deg. targets respectively. Each of the plotted data was obtained by averaging the 16 subjects' detection rates. We regarded that a subject could detect a target when the subject's reaction time fell within the range between $100 \mathrm{~ms}$ and $3000 \mathrm{~ms}$. The reaction time of $100 \mathrm{~ms}$ was regarded as the fastest possible reaction time at which a person can respond to a stimulus presentation as soon as he/she detects the stimulus. Reaction times of $3000 \mathrm{~ms}$ and longer were regarded to be too long for a driver to avoid colliding with a hazardous obstacle. In addition, we discarded the first three responses among 36 data to increase the reliability of the analyses.

We applied a two-way ANOVA to each of the experimental data and Tukey-Kramer tests to each of the pairs of the four experimental conditions for each of the target positions. The results of the ANOVAs showed the main effects for existence of glare source $(p<0.001$ and $p<0.0001$ for $3.9-\mathrm{deg}$ and 5.0-deg respectively) and target luminance contrast ( $p<0.0001$ for both the target 
positions). Tables 2.1 and 2.2 summarize the results of the Tukey-Kramer tests for the 2.9-deg and 5.0-deg targets, respectively. The results of the Tukey-Kramer tests suggested that the target detection rates obtained under conditions with both glare sources was lower than that obtained under conditions without glare sources $(p<0.001$ and $p<0.0001$ for 3.9 -deg and 5.0 deg respectively). Figure 6 and Table 2.1 suggest that there was no significant difference between the other pairs. Figure 7 and Table 2.2 suggest that there was no significant difference between the Both-off condition and $2^{\text {nd }}$-on, between Both-on and $1^{\text {st }}$-on, and between $1^{\text {st }}$-on and $2^{\text {nd }}-$ on.

From the experimental data, a threshold (50-percentile) luminance contrast needed for the subjects to detect targets was determined for each of the two target positions for each of the four oncoming headlight operation patterns. Table 3 summarises the threshold luminance contrasts. For instance, when both the headlamps are turned on, the threshold luminance contrasts were 0.14 and 0.15 for the target eccentricity angles of 3.9 degrees and 5.0 degrees respectively. The result suggested that as the target becomes closer to one of the oncoming headlamps, luminance contrast needed for the target to be detected becomes higher. Based on the above-described results, luminous intensity requirements for ADB systems can be calculated. The calculation results suggested that it was not difficult for automobile lighting manufacturers to develop ADB systems, meeting the lighting requirements, by using the current LED technology. Statistical analyses applied for the experimental data showed that ADB meeting the lighting requirements could significantly improve peripheral target visibility even when oncoming headlight glare exists.

Table 2.1 - Results of Tukey-Kramer tests (3.9-deg target)

\begin{tabular}{l|l|l|l|l}
\hline & Both-off & 1st-on & 2 $^{\text {nd }}$-on & Both-on \\
\hline Both-off & & 0.1430 & 0.3501 & $0.0003^{\star * *}$ \\
\hline $\mathbf{1}^{\text {st }- \text { on }}$ & & & 0.9618 & 0.1991 \\
\hline $\mathbf{2}^{\text {nd-on }}$ & & & & 0.0682 \\
\hline
\end{tabular}

Table 2.2 - Results of Tukey-Kramer tests (5.0-deg target)

\begin{tabular}{|l|l|l|l|l|}
\hline & Both-off & 1st-on & 2 $^{\text {nd }}$-on & Both-on \\
\hline Both-off & & $0.0055^{* *}$ & 0.9855 & $0.0001^{* * *}$ \\
\hline $\mathbf{1}^{\text {st-on }}$ & & & 0.0165 & 0.3053 \\
\hline $2^{\text {nd-on }}$ & & & & $0.0001^{* * *}$ \\
\hline
\end{tabular}

Table 3 - Threshold luminance contrasts

\begin{tabular}{ccccc}
\hline & Both-off & 1st-on & 2nd-on & Both-on \\
\hline 3.9-deg. & 0.09 & 0.12 & 0.11 & 0.14 \\
5.0-deg. & 0.08 & 0.11 & 0.09 & 0.15 \\
\hline
\end{tabular}

\section{Conclusions}

To identify lighting requirements for $A D B$ systems to help drivers detect off-axis potential hazards when oncoming headlight glare exists in a night-time roadway, we conducted target detection tests under various experimental conditions in a laboratory.

The above described experimental results proved that ADB systems, which can illuminate only targets locally and therefore increase the luminance contrasts of the targets, are more efficient lighting methods than conventional forward lighting systems which illuminate the entire visual field to increase drivers' adaptation luminance levels.

Based on the detection rates, we also determined threshold luminance contrast requirements for targets under various experimental conditions. 


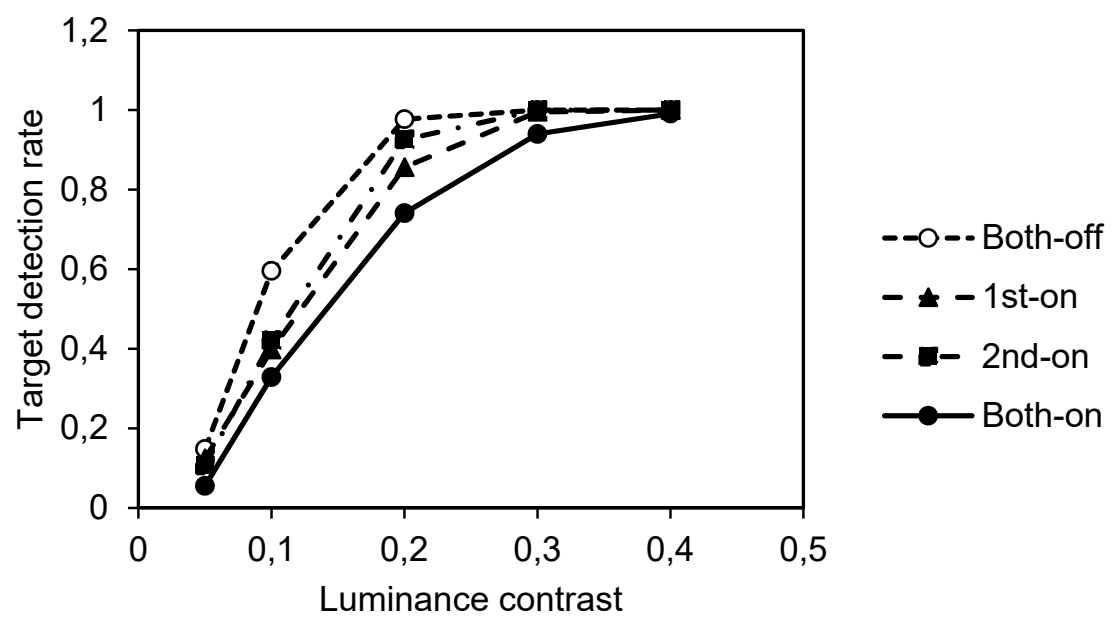

Figure 6 - Detaction rates for 3.9-deg. targets

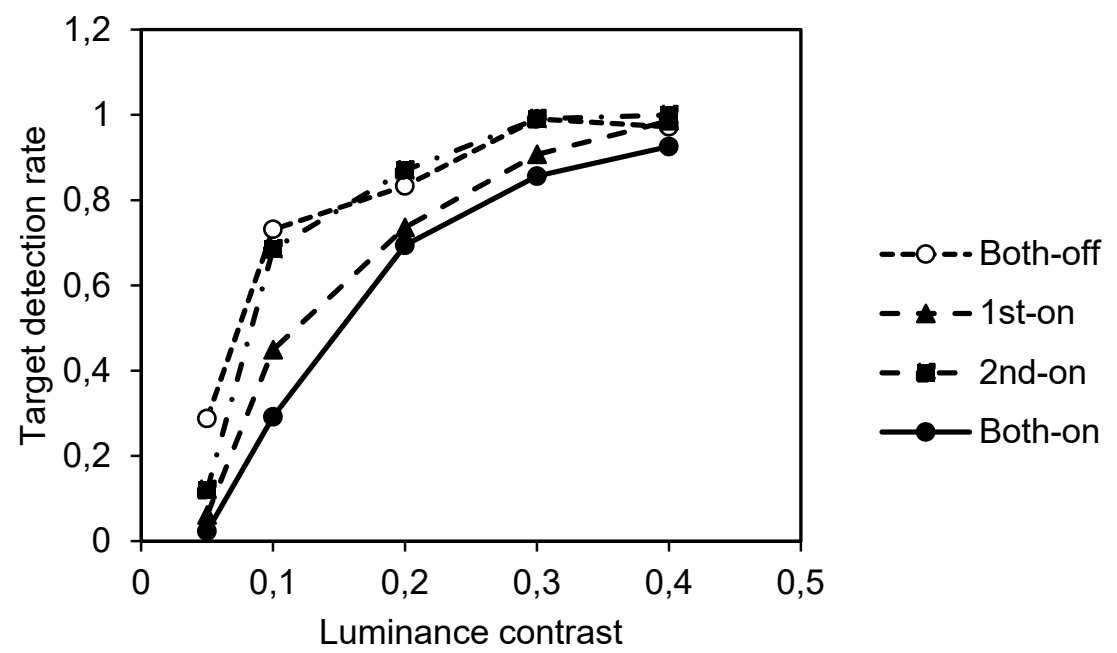

Figure 7 - Detection rates for 5.0-deg. Targets

\section{References}

Adrian, W, 1969. Die Unterschiedsempfindlichkeit des menschlichen Auges und die Möglichkeit inrer Berechnung (Difference sensitivity of the human eye and the possibility to calculate it), Lichttechnik, Berlin, 21, H11, 1A-7A.

Aoki, Y, et al., 2011. Analysis of pedestrian characteristics for a survey simulator to evaluate safety systems (ASSESS), Transactions of Society of Automotive Engineers of Japan, 42, 5, 1199-1204.

Bodrogi, P., Schiller, C., Tran Q.K., 2015. Detection models and their validation for the optimization of ADB lighting distributions, Proceedings of the 11th International Symposium on Automotive Lighting (ISAL), 16, 687-696.

Bullough, J. et al., 2016. Assessment of an Adaptive Driving Beam headlighting system: Visibility and Glare".," In: Report on 95th Annual Transportation Research Board Meeting. Washington D.C., pp. TRB paper 16-2409.

CIE, 1981. CIE 019.22-1981. An analytic model for describing the influence of lighting parameters upon visual performance, Volume I: Technical Foundations, Vienna: CIE.

Terai, N, Iwamoto, K, Akashi, Y, 2017. Veiling Luminance Caused by a Peripheral Glare Source on Extra-Foveal Vision., Journal of Science and Technology in Lighting, 41, 195-202. 